\title{
Eisejuaz: chamán (y relatos de la vida de Santos Aparicio)
}

\author{
Eisejuaz: shaman (and Santos Aparicio's life stories)*
}

\author{
ENRIQUe Flores EsQuivel \\ (Universidad Nacional Autónoma de México) \\ adugobiri@gmail.com \\ ORCID ID: 0000-0002-7940-8142
}

\begin{abstract}
This conversation with Pastor Marcos Delgado, of the Evangelical Mission Assembly of God - from Embarcación, in Salta, Argentina-, took place on Monday night, July 15, 2019. It is regarding Lisandro Vega, the «true Eisejuaz», protagonist of Sara Gallardo's novel Eisejuaz published in 1971, and a member of the same church. The Pastor speaks extensively of the man, as well as Santos Aparicio, another character of great relevance in the novel, and in the «matacos» culture — «matacos» is a name used in the past, in a derogatory manner, to designate the people of Eisejuaz - in a rich, subjective and hybrid survey of the interpreters, the "shamans of God», and of other faces of wichí shamanism.
\end{abstract}

Keywords: Eisejuaz, Wichís, Sara Gallardo, Shamanism.
RESUMEN. Esta conversación con el pastor Marcos Delgado, de la Misión Evangélica Asamblea de Dios — de Embarcación, en Salta, Argentina-, se realizó en el anochecer del lunes 15 de septiembre de 2019, a propósito de Lisandro Vega, «el verdadero Eisejuaz», protagonista de la novela Eisejuaz de Sara Gallardo publicada en 1971 y miembro de la misma Iglesia. El pastor habla extensamente del hombre, así como de Santos Aparicio, otro personaje de gran relevancia en la novela y en la cultura de los «matacos»-nombre con el que antes, de manera despectiva, se designaba al pueblo de Eisejuaz-, en un rico informe, híbrido y subjetivo, de los intérpretes, los «chamanes de Dios»y otras caras del chamanismo wichí.

Palabras Clave: Palabras clave: Eisejuaz, Wichís, Sara Gallardo, Chamanismo.

La primera edición de Eisejuaz - la novela de la escritora porteña Sara Gallardo- apareció en 1971, tres años después de un viaje a la provincia de Salta y de publicar en la revista Confirmado, el 21 de junio de 1968, una breve crónica titulada «La historia de Lisandro Vega» — el «verdadero» Eisejuaz-. Tras leerla en su reedición del año 2013, fascinado por ella, no pude sino conectar en mi imaginación su rico universo visionario con el del chamanismo, y me propuse sumergirme en una investigación de ese tipo que, a pesar de posponerse repetidamente, encontró en un artículo brillante del antropólogo César Ceriani la confirmación de esa sospecha: no sólo el Eisejuaz

\footnotetext{
*Este trabajo se realizó con el apoyo del proyecto "Primitivismo y locura: poéticas de las vanguardias" (PAPIIT-IN400718) y de la Beca al Extranjero otorgada por el Programa de Apoyos para la Superación del Personal Académico (PASPA).
} 
había existido y vivía todavía en la pequeña ciudad de Embarcación, en los límites del Chaco salteño, sino que sus sueños y visiones debían atribuirse al horizonte chamánico y neochamánico wichí.

Sara Gallardo viajó a Embarcación cuando el pueblo era el lugar de encuentro del ferrocarril que venía de Bolivia y el que iba al oriente y se internaba en la provincia de Formosa. Se situaba dentro del gran espacio anterior a la definición de las fronteras, o transfronterizo, conocido como el Gran Chaco y recorrido durante siglos por varios pueblos originarios — nómadas y cazadores recolectores, en un principio, y más tarde sujetos a la colonización misionera (católica y evangélica); sometidos a la servidumbre del peonaje por deudas y el trabajo asalariado, y a la violencia y el terror de la guerra, en el Chaco boliviano y el Chaco paraguayo, o en las provincias argentinas del sur del río Pilcomayo: tobas o qom, wichís o matacos, chiriguanos, pilagás, etcétera- que se enfrentaban y convivían alternativamente en territorios vagamente definidos y cada vez más «reducidos» a las formas violentas o pacíficas de una colonización al mismo tiempo espiritual y material. La escritora, perteneciente a la oligarquía porteña y descendiente directa del general Bartolomé Mitre, escribió así un libro un poco extraño en el marco de la literatura argentina, con un «mataco» como narrador único y como personaje e inspirador absoluto de una lengua extraña en el horizonte de la literatura argentina, comparada a menudo con la lengua de Rulfo, de Arguedas, de Mario de Andrade o de Guimaraes Rosa. Eisejuaz: «Este también» o «Agua que corre», según los significados corrientes o secretos del nombre en la obra —el «el monólogo místico de un indio mataco» (Martín Kohan) o el «alucinado monólogo de un indio psicótico» (Leopoldo Brizuela).

Hospedada en el elegante Hotel Universal, cuyo espacio semiabandonado sirvió después de sede a un club social situado frente a las ruinas de la vieja estación de tren, la autora se entrevistó durante una larga temporada con Lisandro Vega, Eisejuaz, que en ese entonces trabajaba en la cocina del hotel (lavando platos tuvo su primera revelación), era miembro de la iglesia pentecostal escandinava Asamblea de Dios y vivía en la misión evangélica La Loma. La conversación que presentamos tiene como narrador, justamente, al actual dirigente de la Iglesia, el pastor Marcos Delgado, que generosamente nos contó lo que sabía de Lisandro Vega, desde su peculiar perspectiva religiosa y su propia vida y trayectoria como pastor heredero de un rico legado wichí. El universo o los universos de la novela surgen con gran viveza - aunque a partir de otra perspectiva, y más allá de la increíble profundidad y multidimensionalidad poética del monólogo de Sara Gallardo - en su relato, surcado además por las vidas y las experiencias de otros wichís visionarios, situando los sueños, visiones, revelaciones, cantos y rituales de Eisejuaz en un horizonte a la vez cotidiano y alucinante, cómico y dramático, histórico e imaginario. Un horizonte denso, multidireccional y complejo que oscila permanentemente entre el nomadismo y la «reducción», el pasado y el presente, el «salvajismo» y la creencia — entre los antiguos chamanes wichís y el visionarismo evangélico de los llamados «chamanes de Dios»-

La conversación con el pastor Marcos Delgado tuvo lugar en el anochecer del lunes 15 de julio de 2019, en la galería cercana al patio de la Iglesia Misión Evangélica Asamblea de Dios, calle Independencia casi esquina con San Luis, adonde fui conducido por Dora Fernández — educadora y desde hace tiempo investigadora wichí—, y de donde salimos para recorrer el baldío donde se asientan todavía las vías del tren y las ruinas de la estación clausurada, en un pequeño letrero en el cual aún puede leerse: «SE RUEGA NO ESCUPIR FUERA DE LAS SALIVADERAS». Agradezco profundamente a Marcos, pero también a Dora, y a otras personas que me ayudaron en esta investigación en curso — más amplia 
que el relato que se presenta aquí- ${ }^{1}$ Y finalmente, más allá de su empleo directo en la edición de esta extensa relación, y como contribución al análisis etnopoético de Eisejuaz, añado una bibliografía relativa al chamanismo wichí (y toba) y a su avatar pentecostal.

\section{Conversación con el pastor evangélico Marcos Delgado, en Embarcación Misión Evangélica Asamblea de Dios. Embarcación, Salta. 15 de julio de 2019.}

[MArcos:] Yo conocí a Eisejuaz. El nombre de él es Lisardo...

[DORA:] Lisandro.

[MArcos:] Claro, Lisandro Vega. Y él era de los líderes tradicionales de la comunidad wichí. Más que nada de los wichí, eh, él sería de la zona de los weynayek. De allá del norte, son los matacos de Bolivia. ${ }^{2}$ Después de esta zona de entre los dos ríos, están los, también la raza mataca pero que aquí son los propiamente wichí. Como cambiaron el nombre con el tiempo... En la zona les decimos wejwós, o laguleños, los de lagunas, porque viven en las lagunas. ${ }^{3}$ Y después, bueno, están, el indígena de la banda sur del Bermejo, ${ }^{4}$ ¿no? Aquí, Embarcación, se hace una confluencia de las tres, y aun de la cuarta, que sería el wichí, el mataco, del este, que sería de Ingenio Juárez para allá. ${ }^{5}$ Eh, y acá se hace una confluencia de todos esos grupos. Porque, por un lado, estaba el Ingenio, que está acá a 40 kilómetros; por otro lado, estaba acá cerca la comunidad, la misión que formaron los anglicanos, que ahora se llama Misión Chaqueña ${ }^{6}$ de ahí viene ella [señalando a Dora, risas], y mi familia también-.

[DorA:] Él viene de ahí. Yo soy de acá de Embarcación... [risas].

\footnotetext{
${ }^{1}$ Como lo hicieron José Manuel Pedrosa e Isabelle Combés; Rodrigo Montani, muy generosamente; Sergio Coutada y Cristina Vega, la hija de Eisejuaz; sin olvidar, en Tartagal, a John Palmer y a su esposa Tojweya.

${ }^{2}$ Según Antonio Tovar, el territorio de los matacos se extiende, de norte a sur, entre los ríos Pilcomayo y Bermejo, y entre el meridiano $64^{\circ} 31^{\prime}$ y el $61^{\circ}$ de oeste a este. Los «matacos-noctenes» habrían llegado del Chaco boliviano, más allá del margen derecho del Pilcomayo, y su nombre tenía ya en su origen quechua un carácter peyorativo: «El mataco es una variedad de armadillo que se llama también quirquincho bola» (Tolypeutes matacus), porque «su medio de defensa consiste en arrollarse de modo que su cuerpo, doblado hacia el vientre y con la cola ajustada a un lado de la cabeza, quede enteramente cubierto por el carapacho o caparazón, formando como una bola que los perros hacen rodar sin poder hincarle el diente». Los matacos, severos y reservados, contrastan con [otros indios], que sonríen y parecen más abiertos» (Tovar, 1981: 28).

${ }^{3}$ Los wejwós o vejoces eran «los matacos de la orilla izquierda del río Orán», entre Tartagal y el Bermejo. El nombre era «un insulto», y de acuerdo con Tovar, significa, mejor que 'homosexuales', como interpretan otros lingüistas, 'lombrices' o 'con lombrices', o 'los de los gusanos en la cola'. Según el mismo autor -y conforme al mismo informante, nada menos que Santos Aparicio_-, los matacos que venían del norte a trabajar a los ingenios «eran designados con el despectivo nombre de loqotas o yulos», derivado de loqotas o 'cigüeñas': «porque recogen el pescado de la orilla, el desechado por los pescadores» (Tovar, 1981: 2728).

${ }^{4}$ Se refiere al río Bermejo, que pasa por Embarcación y marca el límite sur del llamado Chaco central.

${ }^{5}$ Ingenio o Ingeniero Juárez, localidad situada en la provincia de Formosa y capital del departamento de Matacos, al este de la ciudad Embarcación, agrupa a un importante número de indígenas tobas y wichís.

${ }^{6}$ Población situada en el margen izquierdo del río Bermejo, muy cerca de Embarcación, mayoritariamente wichí, fundada a principios del siglo xx por misioneros anglicanos que avanzaron hasta el Pilcomayo.
} 
[MArcos:] Cierto [risas]. Pero, y ¿cómo se llama? Tu esposo, ¿no?, el pintor. ${ }^{7} J u a n$ es de Misión Chaqueña. Mi papá es de Misión Chaqueña. Después, el pintor, la madre es de Misión Chaqueña.

[MARcos:] Sí, ella era bien amiga con mi mamá.

[E. F.:] Y Eisejuaz venía más bien de los de Bolivia...

[MARCos:] Eisejuaz viene de Bolivia. Él viene muy chiquito de esas migraciones que hicieron. Lo hicieron por tres razones las migraciones, ¿no? Una era por salir de la guerra, el hambre que vino detrás de eso - la guerra de Bolivia y Paraguay, ¿no?-; la otra era porque estaba cerca el Ingenio, y la tercera, que es la que lo determinó, era la confluencia de las misiones evangélicas, tanto anglicana como esta, ¿no? En este caso, ellos tenían contacto con esta. Y bueno, acá Berger Johnsen ${ }^{8}$ cobijó a su familia, la familia de Vega, y bueno, Vega fue haciéndose un líder, creciendo entre los indígenas.

[E. F.:] En la novela habla por momentos de que lo llaman a que ocupe el liderazgo y él dice que no, que nació para ocuparlo pero que no lo ocupará...

[MArcos:] Claro, porque Vega, Vega era de la familia de los caciques tradicionales, ¿viste?, de los caciques ancestrales. Él tenía mucho apego al cacique y brujo. Muchas veces en algunas familias el liderazgo civil, el liderazgo religioso se confluía muchas veces en la misma familia. Y entonces Vega era de ese tipo de líder nato, ¿no? Yo lo conocí, una personalidad fuerte. En su momento lindo en relación con la Iglesia; era una persona de mucho apoyo, edificante, pero cuando se ponía en contra de las situaciones de la Iglesia, situaciones que para él eran injustas, él las atacaba con toda la fuerza, ¿no? Y bueno, había que resistir ese embate de Vega. Pero él falleció, en relación con la Iglesia, en tranquilidad, en paz; reconoció el apego tanto espiritual como cultural con la congregación. Y de tal manera que él murió en paz, tranquilo.

[E. F.:] Ahora, en la novela, aparece también como motivo la muerte de su esposa, que parece moverlo todo y lo pone en una situación de descreencia, de desesperación...

[Marcos:] Claro, falleció su primera esposa... Él justamente reniega de Dios y los que le creen. Nosotros tenemos una creencia pentecostal, y la pentescostal es muy fuerte en el tema de sanidad. Y más en el tiempo pasado, ¿no?, que orábamos mucho por los enfermos y se sanaban. Y justamente la cosmovisión wichí tiene mucho que ver con ese aspecto, o sea, el estar sano en el cuerpo para ellos les da una armonía para toda la vida. Ya, si hay una parte de su cuerpo que afecta, eso desequilibra todo. Por eso ellos buscan mucho, le dan mucha importancia a estar sano... con el curandero, con el brujo, con el pastor, con los hermanos. Si en la Iglesia no hay una solución, corriendo van a buscarla a los medios alternativos, como decimos acá, ¿no? Porque tiene mucha fuerza el tema de la sanidad.

[E. F.:] Y al morir su mujer, se quiebra esa creencia...

\footnotetext{
${ }^{7}$ Juan Gregorio Santoro, esposo de Dorita Fernández, es un interesante pintor wichí.

${ }^{8}$ Johnsen (1888-1945) fue el «pionero» y el fundador de la misión evangélica noruega de Embarcación.
} 
[Marcos:] Claro, se quiebra ese equilibrio de Dios. ¿Por qué Dios permitió que muera, que ella muera? Eso es muy común, en la mentalidad wichí. ¿Por qué se murió, si Dios tiene poder? ¿Dónde está Dios? ¿Por qué yo dejé (que es en el caso de ellos, los primeros), yo dejé tierra, le seguí al gringo (acá le dicen gringo al pastor, ¿no?), le seguí al gringo, cambié mi vida, dejé toda mi cultura, por seguir esta palabra y... - ellos le llaman, al Evangelio le llaman Palabra, o le llamaban antes-, seguir esta palabra y no, no tengo la solución? Así que eso le cambió mucho. ${ }^{9}$ Y bueno, él, Vega, él chocó con el pastor. Su pastor pionero fue el fundador de esta Iglesia, después chocó con el otro pastor que vino después, que es el otro de mucho peso... Se llamaba Berger Johnsen, y el segundo se llamaba Per Pedersen. Y después, por supuesto, con todos los demás, ¿no? Habían tiempos de bonanzas con él y tiempos de conflictos. Hasta conmigo, conmigo también chocó... Y bueno, yo soy el fenómeno acá, porque yo no soy blanco, yo no soy w'ajchá, yo soy descendiente de la cultura wichí. Ellos conocieron - cuando digo ellos son los antiguos, ¿no?, los indios primitivos-, ellos conocieron a mi abuelo, que mi abuelo fue un líder del Evangelio entre los indígenas, o sea, mi abuelo fue el que los... el lenguaraz, el intérprete, que llevaba al misionero y lo hacía conocer al misionero. Aparte, tenía un liderazgo espiritual muy fuerte. Nosotros le damos mucha fuerza a lo místico, a lo espiritual: a la relación, a la experiencia y al control en alguna manera de los espíritus. El curandero, el hechicero, el pastor, eh... Entonces, mi abuelo tenía mucha experiencia y tenía esa manifestación espiritual: hablar en lenguas, orar por la gente que se sanaba... Era muy escuchado el viejo. Él murió en el 75, pero sin embargo su impronta siguió, su huella siguió. Y de tal manera que, cuando yo llegué, los antiguos se acordaban de mi abuelo y eso fue lo que a mí me abrió las puertas. También por supuesto los misioneros hicieron desde Noruega un apoyo explícito hacia mi pastorado, justamente por ser yo descendiente de los primeros de la Iglesia. Y bueno, así que para los indígenas yo soy como el blanco [risas]... Es el fenómeno que acá... de que yo vengo a ser el primer pastor nativo, mestizo, que tiene, que tiene aceptación.

[E. F.: ] Y heredero de un liderazgo...

[Marcos:] Muy fuerte, sí. Sí, porque el abuelo también era de esos líderes ancestrales.

[Dora:] ¿Y cómo se llamaba tu abuelo?

[MArcos:] Santos Aparicio.

[E. F.:] ¡Ah, él! Yo le hablaba a Dorita de él... Él aparece en la novela como un gran personaje, con otro nombre: Vicente Aparicio. Eisejuaz siempre va a buscar para salvarse a Aparicio. ¿Él era? ¿Y él vivía acá, y se fue y volvió, o cómo era su historia?

\footnotetext{
${ }^{9}$ Isidro Vilte, «mataco nacido a orillas del Pilcomayo» e «informante» de Tovar, educado por los anglicanos en Algarrobal, sufrió algo similar al morir su mujer muy joven, en su primer parto: «Dejó la misión y pasó una época algo desordenada, que él presenta como de grandes pecados, en Tartagal» (Tovar, 1981: 33).
} 
[MArCos:] ¿Mi abuelo? Claro, mi abuelo... él conoce al fundador acá en el año... más o menos... A ver, el misionero vino acá en el 14. Mi abuelo tiene diez años. Mi abuelo lo conoce, se convierte al Evangelio cuando él tiene dieciocho, o sea, más o menos el 22 tiene contacto y ahí entra él a la Iglesia. El noruego le enseñó a leer y a escribir a él, y a partir de ahí empiezan a visitar las comunidades. Pero acá a la vuelta nomás, en el Ingenio sencillamente y aquí en Pichanal. Entonces, más o menos a partir del 25 , por ahí comienzan a visitar la zona de las Tres Fronteras, ya en el norte -Bolivia, Paraguay y Argentina-, y bueno, cuando estalla la guerra, ellos están allá en esa zona. Así que ahí seguramente tomaron contacto. Pero el abuelo es de esta zona. Y bueno, como premio de este..., así, recompensa, agradecimiento de este, de que mi abuelo estuvo con él siempre, el misionero le regaló, acá en la esquina del frente, le regaló un terreno que él tenía, que era de él. Claro, cuando vino el gringo con su plata, él compró todo este terreno donde está acá la iglesia, ¿ve?, compró el terreno del frente, de calle a calle, ¿no?, todo el..., la línea sobre la San Luis, y unos terrenos así separados por ahí. Bueno, después los fue vendiendo porque Noruega fue conquistada por los alemanes, él quedó sin sostén económico y tenía que buscarla. Y mi abuelo siempre le ayudó en eso. Él y otro indígena de apellido Villafuerte. Entonces, el misionero le regala a mi abuelo aquí el terreno de la esquina, y a Villafuerte le regala el otro que está acá a media cuadra, sobre la San Luis.

[Dora:] Villafuerte, ¿el Orlando?

[MARCos:] Sí, ese lo regaló el misionero. Y bueno, después el misionero muere por la tuberculosis que se contagió de los contactos con los indígenas y mi abuelo queda acá. Él queda aquí viviendo en la esquina, él tomó el liderazgo de la Iglesia cuando falleció el pionero, el fundador, hasta que vino un misionero sueco que después fundó allá la obra del Kilómetro $6,{ }^{10}$ Ule Johnson. Con Ule tuvo problemas, conflictos con mi abuelo, así que mi abuelo queda fuera de la Iglesia, fuera del ministerio, eh... La parte wichí es la que lo apoya a él, y bueno, mi abuelo es cuestionado por los otros, los otros grupos étnicos de la zona, o sea, tobas, y los otros que venían de allá de la zona del Pilcomayo. En ese tiempo, ¿no? Y bueno, los matacos, los antiguos wichí ellos apoyaron a mi abuelo todo el tiempo. Y Vega era muy, muy fanático... él era también muy amigo con mi papá, así que Vega conmigo tenía...

[E. F.:] ¡Muy cercano...! Hay una escena en la novela, un momento en la novela en donde, muy desesperado Vega, decide emprender, ir a pie a buscar a Aparicio, que estaba viviendo lejos — siempre lo llama «el hombre de la YPF»—. ${ }^{11} \mathrm{Y}$ va con él y tiene un encuentro impresionante en la novela donde toman cebil. ${ }^{12} \mathrm{Y}$ él va desesperado porque sus «mensajeros» ya no le hablan. Y después de la ceremonia - bueno, «ceremonia»— en que toman el cebil, vuelve a reencontrar,

\footnotetext{
${ }^{10}$ Misión ubicada 4 kilómetros de la ciudad de Tartagal, compuesta de indígenas chorotes, tapietés y wichís.

${ }^{11}$ Yacimientos Petrolíferos Fiscales. Compañía petrolera estatal con un protagonismo especial en la novela.

${ }^{12}$ Sobre el cebil, entéogeno empleado en múltiples regiones sudamericanas, véase Larraya (1959).
} 
vuelve a escuchar a los «mensajeros». ${ }^{13}$ Pero todo con Santos Aparicio, que en la novela es Vicente Aparicio.

[MArcos:] Bueno, yo... Hay una parte que no es real, ¿no? ¿Por qué? Porque... Hay dos cosas que... Por un lado, Sara Gallardo le gustaba lo místico, y que no esté ligado con el cristianismo no católico. Porque acá lamentablemente estamos en un gobierno que discrimina todo lo que no sea católico. Y antes era peor. Por otro lado, el pensamiento wichí, el pensamiento de los informantes wichí, muchas veces se salía de las cosas reales. Se iba, y mezclaba... Y Vega era de esas personas que, que... Uno no podía seguir la historia de Vega porque él la mezclaba, él mezclaba los tiempos, mezclaba las personas, mezclaba los lugares. Entonces ellos, lo que cuenta ahí - yo leí el libro, lo tengo incluso, y lo he buscado el libro ese hasta que lo conseguí en Buenos Aires en una librería de libros usados, viejos, encontré una edición original-. Pero yo pensaba, tanto que hablaban de Eisejuaz, que era algo interesante, pero cuando lo leí era, para mí era leer la misma forma de cuento de las gentes de antes, ¿ha visto? No, no era, no me aportaba nada nuevo. Sí me aportó en el sentido este de que él hizo escribir, él fue el informante de esta chica cuando él estaba en un momento espiritualmente bajo...

[E. F.:] Algo notable en el libro, y que tiene que ver con lo que hablabas de los espíritus y todo eso, es que aparece, es un libro completamente visionario, lleno de sueños, de visiones, de voces... Pero eso existía, de una manera adaptada al pentecostalismo...

[MARCos:] Sí, hay un sincretismo, sí, sí. Evidente el sincretismo entre las creencias tradicionales wichí con el pentecostalismo como ellos lo percibieron. Porque el tema... yo acá como pastor pentecostal y a la vez indígena, eh, muchas veces tuve que... ¿cómo le puedo decir?, reenseñar, revisar lo... Una cosa es lo que dice la doctrina pentecostal, cristiana; otra cosa es cómo lo perciben ellos, muchas veces. Por ejemplo, te doy un ejemplo: una enseñanza fuerte que hubo un tiempo acá era que no tenían que tomar mate para que no se contagien la tuberculosis. Entonces, era la palabra santa del misionero... ¿Qué hicieron los líderes? Fueron a secuestrar los mates y las bombillas de toda la comunidad, de todo el campamento, y le trajeron al misionero la bolsa llena de bombillas. También está en el Populi ${ }^{14}$ no tomar, no tomar vino, que tomar vino es pecado. Bueno, en la Biblia en ninguna parte lo dice. Sin embargo, es tan fuerte la enseñanza en contra del alcoholismo que para ellos no tomar vino, no deben jugar fútbol, no deben participar de las fiestas patronales, católicas, ¿no?, como es que hay acá. Eso, todo eso es pecado y en su tiempo era, era motivo de sanciones disciplinarias dentro de la Iglesia. Una cosa es la enseñanza de la Iglesia, la enseñanza doctrinal, y la otra cómo lo reciben.

[E. F.:] En el libro eso también aparece... Porque él era, por lo que he leído, un hombre muy riguroso, se encargaba de la disciplina justamente, cuando estaba cerca de la misión, ¿no? Pero en otros momentos es cuando se va, se desespera y justamente se pone a beber alcohol, se va al monte, vive como antes...

\footnotetext{
${ }^{13}$ Transcribo un ragento de esa escena del cebil al final de esta conversación, en el Apéndice 2.

${ }^{14}$ Vox populi.
} 
[DORA:] ¿Y no era chamán?

[MARCos:] Medio chamán era.

[E. F.:] ¿Sí era un hombre muy visionario él, o eso es parte de...? ¿Sí era «medio chamán»?

[MARCos:] Sí, para la forma nuestra sí. Para la forma del criollo, del moderno, sí, sí.

[DORA:] ¿Y tu abuelo?

[MARCos:] Él también, también descendía de los brujos. ¿Sabes quién es pariente de mi abuelo? El famoso Anselmo, allá en Misión Chaqueña. Eh, él era, o sea, yo vengo de esa familia. Nosotros por ejemplo tenemos, tenemos una creencia que los espíritus de los curanderos se traspasan de forma hereditaria, dentro de la generación. Entonces, muere el abuelo, busca a alguien cercano, sea un hijo, sea un nieto, para que pase el espíritu del curandero. Así que mi abuelo venía de la tradición, y él tenía que ser el curandero. Así que él renunció al espíritu del curandero para mantener el espíritu de Dios. Y el poder que le daba el espíritu de Dios. Porque hay un poder que él tenía. Mi viejo era muy, muy escuchado, muy valorado. Mi abuelo, ¿no? La gente me cuenta hasta ahora que el viejo, por ejemplo, se levantaba, empezaba a danzar y la gente empezaban a llorar y caían... Un poder así, pentecostal, muy fuerte. Pero también el viejo tuvo sus caídas. Mi abuelo tuvo sus momentos de cristianismo bajo, y como él... Un aspecto de la cultura wichí es el alcoholismo, así que mi abuelo era recurrente su alcoholismo. Y bueno, ahí parece que se encontró con Vega, o con algún otro, ¿no? Y mi abuelo, sin embargo, él fue un tipo muy inteligente, muy despierto, y entró a trabajar a la empresa de YPF. Fue uno de los primeros indígenas en documentarse, todo eso gracias a la ayuda del misionero acá. Y cuándo él muere, murió el misionero, bueno, mi abuelo quedó en el aire, Trabajó, sí, con los otros wajchá, con el Pedersen, con Johnson, después con otros misioneros, hasta que murió en el 75. Él ayudó a fundar varias iglesias entre los indígenas y también en la ciudad de Tartagal.

[E. F.:] Al final de la novela, cuando Eisejuaz está cerca de la muerte, la gente, las mujeres se acercan a él para buscar que las ayude o las salve de alguna manera, pero él las manda con Aparicio, les dice que lo vayan a buscar a él, al «hombre de la YPF»...

[MARcos:] Porque él vivía en Vespucio, ${ }^{15}$ en el campamento, de acá unos cien kilómetros de acá al norte. Y ahí él estaba a cargo de un terreno donde estaba una antena de radio, el abuelo. Aparte, él era jardinero, ahí en el campamento. Y bueno, después se jubiló de YPF y trabajó un tiempo con el municipio de Tartagal, también cuidando la plaza central.

$* * *$

[DorA:] ¿Y qué es Eisejuaz? de YPF.

${ }^{15}$ El Campamento Vespucio es una población fundada en 1929, junto a las instalaciones petroleras 
[Marcos:] Ehh... Mmmm... Verdad que no me acuerdo. Verdad que no me acuerdo. Yo pregunté una vez, no sé. Lo tendré por ahí, guardado... Porque se escribe: Ei-sejuaz. Ei-sejuaz. Pero las variantes del norte, por eso es que acá no le podemos agarrar la vuelta.

[Dora:] Pues yo busqué en el norte, pero no, no vi nada ahí.

[Marcos:] No, eh... Es una forma... Ese era el apodo que él tenía. Siempre a él lo conocimos como Eisejuaz. El aborigen más... el antiguo, ese no lo conocen por el nombre. El nombre es para el criollo, para hacer trámites. Ahí dentro de su comunidad es el apodo.

[E. F.:] En la novela dice que cuando escucha gritar su nombre por unos blancos que aparecen, para él es terrible, porque dice que eso no debe gritarse ni decirse, ¿no? [Risas.] Pero ¿sí era llamado así?

[MArcos:] Sí, acá lo conocimos como Eisejuaz... Isejuaz, le dicen. No Eisejuaz. Isijuaz.

[DorA:] Isijuaz es como «una pequeña luz».

[MARcos:] Por eso, por eso es que también hay... Porque el wichí, yo lo pregunté y no lo sabe identificar, como está en el libro. Pero como era, yo conocía a Eisejuaz, no Eisejuaz sino Isijuaz. ¿Así era? ¿Más o menos?

[DorA:] Isijuaz.

[E. F.:] Y como dice Dora, es «una pequeña luz».

[Dora:] Sí, «una pequeña luz». O «una luz», también. ${ }^{16}$

[MArcos:] Yo creía que... Si mal no recuerdo, era «el que brilla» o algo así.

[DORA:] Sí.

[MARCos:] Pero era... Eisejuaz ha sido el primer concejal indígena de la historia de Embarcación. Él fue por la parte peronista. Después, hay otro que era Ricardo, se llamaba, él fue de la parte radical. También concejal. Pero, bueno, justamente el gran cuestionamiento aquí de la familia es que, siendo tan famoso el cacique, tantos miles de libros escribió esa mujer — se hizo la plata con Eisejuaz-, él ha vivido y muerto pobre. Cuando él más necesitó, ninguno, ni los políticos, ni los investigadores, estuvo con él. Eso, bueno, eso es típico acá, en la zona, también.

[MArcos:] Isejuaz, él era el encargado de..., como era cacique ancestral, él era el encargado de hacer todas las ceremonias tradicionales... ¿Querés grabarlo? Grabalo... Isejuaz, él era encargado de hacer todas las ceremonias tradicionales de la comunidad donde él vivía, en Misión La Loma, en relación con la Iglesia y también con la comunidad. Por ejemplo, cuando llegaba una autoridad... Hay

\footnotetext{
${ }^{16}$ Unos días después, en Tartagal, el antropólogo inglés John H. Palmer, autor de La buena voluntad wichi: una espiritualidad indigena, residente en Tartagal y casado con una wichí, suscribió esa interpretación.
} 
una foto que yo tengo, en ese archivo fotográfico, bueno, hay una foto rara de un gobernador de Salta, en la época de la dictadura, un poco antes del 76...

[Dora:] Ragone.

[MARCos:] Ragone, justamente. Él fue a visitar Misión La Loma y allá Eisejuaz lo viste a Ragone - a un gobernador acá importante - , lo viste de cacique. Le pone una vincha las plumas, le regala la artesanía... Y lo mismo hacían aquí en la iglesia con el pastor. Así que hay una foto adonde a Per Pedersen justamente Vega lo viste, a él, de cacique. Así que él era el encargado de eso. En el año 2003... No, 2004, 2005, por ahí, vino acá una delegación de... vino a Argentina una delegación de indios de Estados Unidos, de la zona de Hawai, de la isla de Hawai, y también de Estados Unidos propiamente. Apaches vinieron. Tenían esas plumas largas, hasta la cola, ¿viste?, de esas tiras de plumas. Y se bajó un indio de la camioneta y... Bueno, a mí me piden los pastores que lleve una delegación indígena de acá, que los lleve acá a Orán. ${ }^{17}$ Porque ese grupo de indios venían a Orán, y ellos querían hacer una ceremonia de pedir permiso a los «dueños de la tierra», para pasar por su tierra. Eh, había una conferencia internacional de pastores, de todos... vinieron de todos lados, a Buenos Aires. Y este grupo vino, pero antes de ir a Buenos Aires, ellos querían pasar por la tierra indígena y pedirle permiso a los verdaderos dueños de la tierra. Así que se bajó ahí, en Orán, un indio grandote, así, parecía un gorilón [risas], con una nariz gruesa, y empezó a danzar con esa danza que ven en la televisión. Y Vega, yo le avisé un poco a lo que íbamos, así que él se puso la ropa tradicional wichí, con una chiripa hecha con, ¿cómo se llama?, con cháguar, ${ }^{18}$ se puso unas vinchas con plumas, se sacó la camisa y quedó descalzo y estaba con la chiripa nomás - la chiripa es como una falda-. ${ }^{19}$ Así que el viejo este, el hombre este, el pastor de Hawai se puso a danzar [risas], y bailaba así con esa danza antigua, ¿no? Y gritaba: «Ooooiii...». Y bueno, había alguien que nos traducía del inglés al castellano, y otro traducía al indio ese. Y ellos le pedían permiso al dueño de la tierra. Así que Vega lo mandamos al frente [risas], y él estaba solito, todos nosotros estábamos detrás... En ese tiempo no teníamos cámara, no hay nada filmado. Y después Vega empezó a danzar también [risas sonoras].

[DorA:] [riendo] ¡El pastor a dancista...!

[MARCOS:] ¡Los dos pastores dancistas...!

[Dora:] [riendo] ¡Qué lindo!

[MArcos:] Porque era... ¿Viste eso de que el cristianismo le quitó la cultura, y todo eso? Bueno, ahí, ¿no?, ahí está. Los dos líderes. Vega estaba en la Iglesia, él cuando hacía su aporte como cristiano era muy respetuoso, respetable era lo que hablaba. Y el viejo, el pastor este de Hawai lo agarra a Vega y lo arrima, y pone nariz con nariz, ¿no? - Vega también la tenía una nariz finita, ¿no? [risas]_. Y lo pone así y lo sopla como toro, ¿no?, y dice que así pasaba su

\footnotetext{
${ }^{17}$ La ciudad de Nueva Orán, en la provincia de Salta, es otro referente en la novela de Sara Gallardo.

${ }^{18}$ Planta semejante a la yuca, con hojas de espada, característica del Gran Chaco. Entre los wichí, son las mujeres quienes desfibran sus hojas, e hilan, tiñen, tejen y comercializan su confección y sus artesanías.

${ }^{19}$ Poncho o medio poncho de tela utilizado por los indios como calzoncillo, a instancias de los misioneros.
} 
espíritu a... recibía el espíritu de él. Así que, así se hicieron amigos y... Así era, ese era el Vega que yo conocía, como líder ancestral. Así que esa era su función, hacer mantener la identidad cultural. En la escuela también, en la escuela que está en La Loma, él también iba a hacer sus presentaciones, así como líder ancestral. No, el Vega era... Era un líder, líder nato. Eh, muy respetado en la comunidad, muy querido también. A pesar de que conmigo, tuvo conflicto conmigo, nosotros solucionamos el conflicto, hemos estado juntos. Incluso te digo más, él, así como me hizo el problemón a mí — porque me fue a los medios acá, los medios locales, los medios de comunicación locales, me fue a «escrachar», como decimos en la Argentina-, después vino una vez, me dice: «Marcos, yo con vos todo bien. Pocas palabras, pero para que estemos bien yo te pido perdón». Listo, así. En cortito, ¿no? Y yo no necesito tampoco mucho protocolo. Nos dimos la mano, y siempre, a partir de ahí estuvimos juntos, hasta que él murió. Así que ese es mi recuerdo con el viejo Vera.

[E. F.:] Ahora, hay algo que nos llamaba la atención... Veíamos que, en la novela, hay un personaje que aparece, que es el «Paqui». Es un personaje al que cuida Eisejuaz, al que Eisejuaz se siente obligado a cuidar. Y es un blanco, pero es un blanco completamente degradado, ¿sí? Ese personaje al que él le da todo lo que él no tiene, y todos los demás lo condenan por hacerlo, es el peor de todos. ¿Cómo se puede entender eso?

[MARcos:] Usted sabe que yo estuve, estuve preguntando quién era, y no, no me han sabido responder la gente de antes, quién era el Paqui, sí. Yo estuve preguntando en La Loma. Porque me parece raro ese personaje. Y por eso le digo, eso está dentro de lo... de las invenciones también, tanto de él como de ella. Así que no sabemos bien hasta dónde infló la información, la acomodó, ¿viste?, para hacerla más...

[E. F.:] Pero como que, dentro de la Iglesia, es una misión extraña la que asume él, la de cuidar a ese hombre... ¿O no es tan extraña?

[MARCos:] Sí, el aborigen recibía. Recibía, recibía todo el tiempo. Y más en ese tiempo. No era de dar. Un tipo así de ayuda como lo que cuenta él, ese hombre, eso lo daba normalmente el misionero, ya sea en forma directa o a través de su sistema de obreros. De obreros y de... líderes locales detrás de la Iglesia. Entonces, no lo hacía cualquier persona. Hoy sí, hoy es normal que un hermano de su bolsillo saque plata, saque ropa, los regale, pero antes todo lo recibían, esperaban que el misionero lo dé. O la Iglesia, ¿ve? Entonces, por eso me parece raro. ¿Quién es ese hombre? Y encima blanco... No era de la comunidad... Y era... se hubiera rechazado en su comunidad también...

[E. F.: ¡Blanco....! ¡Pero es el más degradado..., y el más físicamente degradado...! $\mathrm{Y}$ al final se convierte en una especie de..., es venerado de una manera supersticiosa el Paqui. Lo llevan en un camión como un milagrero, como alguien que hace milagros, después de que podemos ver que es el peor de todos, el más cínico y el más hipócrita, el que más daño le ha hecho particularmente a Eisejuaz. Entonces, es muy simbólica su personificación: el más supersticioso, el peor, es ese blanco al que protege Eisejuaz. 
[Marcos:] Porque este blanco era, estaba identificado con ellos. ${ }^{20}$ Yo lo que le pude, más o menos, relacionar con lo que él cuenta, y es una historia que a mí me contaron... Mi abuela, la esposa de Santos Aparicio, ella era una india mataca blanca, de ojos claros, media agringada. ${ }^{21} \mathrm{Eh}$, y ella tenía un pariente que era un curandero de esos... nosotros acá decimos bravos, de esos curanderos fuertes, de espíritu fuerte, que vivía en los cerros, cerca del río... O sea, vos ves el puente, donde está el río, ¿no? Para el otro lado, hay una zona que se llama La Hibernada. Por esa parte, vivía. Y él vivía bien a lo indio. Y él era un hombre rechazado, así... Un hombre querido y odiado a la vez. No querido: buscado pero era temido, odiado. Porque trabajaba con espíritus fuertes. Y... incluso él vivió hasta hace un tiempo atrás. A mí me contaban... Y esa historia me la contó, primero gente de La Loma, de ese abuelo - tío abuelo, dicen que era mío-. Y yo no... yo después empecé a oír a mi familia, así, que existe. Pero era un hombre que era un ermitaño, ¿viste?, viviendo en las cuevas... Un tipo raro. Y bueno, como él puede ser que haya sido... O yo, yo tenía otras dos opciones, recién hoy, mirando, lo puedo... lo digo así porque nunca hemos conversado exactamente del libro...

[E. F.:] Pero él no era blanco... Además el Paqui no era brujo. El Paqui no creía en nada...

[Marcos:] Claro, pero ve, ahí están las cosas, ¿ves? Yo lo leí el libro una vez nomás, no lo estudié mucho. Pero lo que sí, es la historia que me contaron...

[E. F.:] Es terrible que Eisejuaz se tenga que hacer cargo del que lo trata peor, del que más lo maldice, el que más se burla de él. De él se hace cargo, como si esa fuera la misión que se le confía. Y los otros también se burlan de él cuando la cumple... Y hay otra cosa: cómo la gente que se acerca a Eisejuaz comienza a morir, en la novela...

[MARCOS:] ¿La gente que se acercan a Vega...?

[E. F.:] Sí, como si en vez de curarlos les trajera una especie de maldición...

[MARcos:] ¡Claro, ahí...! Es que pasa que está muy relacionada la visión del cristianismo que ellos tienen. Y justamente eso es... Acordate que él estaba en su tiempo de un cristianismo cuestionado, y él mismo... Se hace muchas veces la gente esa pregunta: "Ahora que estoy lejos de Dios, todo me sale mal. Y se me mueren...». O sea, el indígena es muy, muy centrado, todo a la vuelta, egocéntrico. Entonces, mientras él está bien, todas las cosas le van bien, pero si él está mal, todo le va mal, a la vuelta. Y entonces se analiza: «¿Por qué a mí?». Y ese constante victimizarse es muy común... Por ejemplo, dicen: «Yo estoy solo. Nadie me visita. Nadie me quiere. Nadie me ayuda». Eh... «Todo me sale mal. No tengo trabajo». Eh... «Hay enfermedad en mi casa, en mi familia». Entonces, muchos dicen: «Vuelvo a la Iglesia. Porque estoy mal con Dios».

\footnotetext{
${ }^{20}$ La visión de Marcos se aleja del personaje de la novela..., sólo para establecer otra conexión alternativa.

${ }^{21}$ «Aparicio está casado con Ermelinda Luis, amable y excelente mujer, y de ella tiene siete u ocho hijos». (Tovar, 1981: 32). Y en nota a uno de los relatos dice que «es relato de Ermelinda de Aparicio, que, sin duda es más popular y auténtico» que el del propio Aparicio, «aunque éste era más fácil informante» (Tovar, 1981: 129).
} 
[E. F.:] Ahora, ese personaje también es muy interesante. Ese hombre que se iba... que vivía en la cueva... ¿Tío abuelo? ¿Cuál era su nombre?

[MARCos:] No me acuerdo. Creo que era... No, verdad que no me acuerdo...

[E. F.:] Quiere decir que era muy fácil $-\mathrm{y}$ eso se ve en la novela- el poder volver al monte, o sea, alejarse de... Había una distancia muy corta, hace poco y además una distancia corta para volver. No era necesario irse hasta el Pilcomayo...

[MARCOS:] El río es parte de su historia...

[E. F.:] Era como recaer, volver a lo anterior...

[MArcos:] Exactamente. Y ese hombre nunca fue cristiano. Nunca aceptó. Él se apartó de la comunidad porque justamente se han ido al cristianismo.

[MArcos:] Sara estuvo acá varios meses, viviendo. Vino dos o tres veces, dicen... Creo que ella venía de Bolivia, incluso. Y ella salió de una historia real, ¿no? O sea, habla de nombres reales: Berger Johansen, Santos Aparicio, el hotel donde ella paró acá, ${ }^{22}$ en ese tiempo que estuvo. Son situaciones reales, con nombres de gente de la ciudad que son reales. Y acá era centro de... era un centro neurálgico por el ferrocarril. Entonces, acá se unía el ferrocarril del este y del norte, de Bolivia. Entonces, Embarcación en ese tiempo era una ciudad bastante importante, de tal manera que era... estaba compitiendo con Orán. A Embarcación lo tira al suelo que han hecho el hospital regional en Orán, una, y la otra cuando el ferrocarril lo cerraron. Entonces Embarcación quedó perdido en el mapa.

[E. F.:] El hospital es importante, por la enfermedad de la mujer. Es muy dramático cuando Eisejuaz narra cómo la tiene que llevar tan lejos, a Salta, con tanto sacrificio...

[MARCos:] Y era, en esos tiempos era más difícil el acceso a La Loma. Cuando suba, va a ver que es difícil. Y cuando era... En esos tiempos era, era más alta, era un camino de huella, no estaba consolidado como ahora. No tenían instalación eléctrica, no tenían agua... En el 62 empezaron a vivir, a ir a vivir allá, arriba. Y él fue uno de los primeros que se fue. Hizo patria ahí, en ese monte. Lo que era la Misión La Loma. Y Vega me dijo una vez, antes de morir; me dice: «Dios me ha castigado a mí de la peor forma» — me dijo, más o menos, con palabras más brutas me lo dijo, ¿no?-. «Porque yo he perdido mi esposa; después me he casado con otra, también se me ha muerto; se me han muerto todos los amigos, y yo he quedado solo». Y él estaba... A él, a él lo sentaban, así, en un sillón... Él andaba con anteojos de esos protectores de los ojos, ¿viste?, todos cerrados, a la vuelta; antiparras, transparentes... Y eso nomás tenía. Y él, a veces la familia se descuidaba, ahí... Y él estaba ahí. Y entonces no tenía ya control del cuerpo, se orinaba, se hacía pipí... Y así, él me dijo así: «Yo estoy solo. No había habido más castigo, más duro que esto», me dijo. «Que morir

${ }^{22}$ Se trata del Hotel Universal, hoy en día abandonado y transformado parcialmente en un club social. 
solo. No tengo amigos, no tengo a nadie. Estoy... No puedo hablar con mi hijo, con mi nieto. No puedo. No es lo mismo», me dice. Me dijo esa... Así que, cuando él partió, bueno... Murió solo. Yo vi a un Vega, un hombre famoso, pues lo vi... lo vi solo. El velorio fue muy poca gente. No vino nadie. Sólo yo estaba de... como líder, autoridad. Muy familiar, así... Nos llevamos el cuerpo a la iglesia, la mitad de la congregación estaba en la iglesia. Así, muy solo. Y él fue uno de los últimos ancianos en morir, de la primera generación. Y yo, bueno, yo pienso que sí, ¿viste?, que había sido un castigo, digamos - una forma de hablar, ¿no?- , esa muerte que tuvo él. Y verdad, ¿no?, esa soledad, yo lo vi, yo la vi, cuando iba a visitar La Loma, lo vi al viejito, sentado en su... en su casa. Y a veces me quedaba a conversar un rato con él; otras veces no podía y pasaba de largo. Pero... verlo ahí, sentado, solo... Siempre tengo esa imagen de esa soledad que él pasó, siendo lo que fue, ¿no?

[Marcos:] Vega tuvo, así, ese tipo de... de mala suerte, digamos, ¿no?, como dice la gente [risas]. Le gente que se le acercaba de verdad, él mismo decía, y la gente decían: "¿Qué pasa, Vega? Todos parece que él los maldice», decían. Ahí yo tengo una historia que me contó un indígena, ahí de La Loma, cuando yo tengo conflicto con él. Porque yo sanciono al yerno de él, que era... yo lo tenía de líder en la Iglesia [carraspea]. Entonces, dice, me cuenta, al tiempo, que viene Vega y me sopla en la nuca. Yo pasaba cerca de él y... [sopla]... hace un soplo. Y bueno, según la forma de pensamiento de los indígenas, esa era una maldición que me tiraba para que yo me muera seco, dice... O sea, para que me enferme, me, me, me... enflaquezca y me muera. Y pasaron los meses [carraspea], con Vega ya nos arreglábamos todo, y viene este líder y me dice: «Che, Marcos», me dice — así, porque así me dicen a mí acá, ¿no?; no «pastor», ni «hermano»: «Marcos»-... «Che, Marcos», me dice, «a vos, a vos te han soplado la nuca», me dice. Y entonces, me cuenta. Me dice: «Vos sabés que ese día que hemos estado en la reunión en la iglesia y vos lo has disciplinado», dice, «a, a Chávez, eh, Vega ha pasado al lado tuyo y te sopló la nuca. Nosotros hemos visto», dice, «eso». Me dice así, con esas palabras, el viejo. «Y, y eso, en la mentalidad de nosotros», dice, «eso es... significa una maldición, y una de las peores maldiciones que te han tirado». Y yo le digo: «Pero ¿qué?, ¿es curandero Vega?». «Sí», dice, «nunca ha dejado el curanderismo» [carraspea] [risas]. «Él un tiempo está en la Iglesia, un tiempo acá en el mundo, pero todos saben que él es curandero», me dice. «¡Ah, mirá vos!», le digo. Y... «Pero ¿sabés qué dice la gente en La Loma?», me dice este hombre. Me dice: «Vos sos pastor de verdad, aquí», dice, «puesto por Dios, porque con la maldición que te ha tirado vos ya tendrías que estar enfermo, ya para morir. Pero ahí estás vos», me dice, «caminando todavía [risas], y estás más gordo», me dice [risas]. «Así que ahora nosotros sabemos que Dios te ha puesto acá», me dice a mí. «¡Ah!», le digo, «¡Mirá vos si yo me moría!», le digo. «iSi quiera me ibas a avisar pa que esté orando!», le dije [risas]. «No», dice, «nosotros estamos probando», dice, «si de verdad vos sos puesto por Dios», me dice el hombre [risas]. Por eso que, como te dije al principio, la mentalidad de acá, eh, nosotros tenemos muy presente, tanto como cristianos como no cristianos, tenemos muy presente la actividad de los espíritus. Entonces, ese tipo de historia que me han hecho a mí lo hicieron, 
también me lo contaron en relación a los misioneros antiguos. Y pastor que no tenía esa manifestación espiritual, y así, ellos no lo consideraban pastor puesto por Dios. Así que... Y una de las cosas era este choque permanente con el curanderismo. Los curanderos se convierten al Evangelio y ellos entregan todos sus... acá les decimos herramientas, ¿no? Una yica - una bolsa hecha con artesanía— ${ }^{23}$ llena de objetos... Y entregan todas sus cositas, ¿no?, con las que trabajan curanderismo. Y bueno, nosotros las quemábamos... Cuando yo vine acá, habían dos bolsas llenas de herramientas de curandero que estaban guardadas acá en la iglesia, acá. El misionero tenía como, como reliquias, así, como trofeos, ¿viste?, de guerra, como decir. Y cuando yo lo vi, y yo pregunté: «¿Qué es esto?», y lo sacamos, así, y los hermanos se asustaron: «No, este es curanderismo», decían. «Este hay que quemar». "¿Por qué el misionero lo guarda», dice, «Este ha de tener espíritu aquí adentro?». Por ejemplo, había un palito así, que tenía punta en los dos, en los dos lados tenía punta, así afilada, y dicen que esos palitos recogían espíritus [risas]. Verdad que yo no sé... yo no. Para mí era un palito común. «No los toques. No, no, no». Así que, bueno, yo para hacernos respetar sus costumbres lo hicimos quemar... Y siempre que a mí me llamaban me entregaban objetos de... como dicen herencia, dicen acá. Objetos del pasado, ¿viste? Una hebilla... A veces, habían cosas de la época de los soldados de la guerra, la persecución. Y en otros lados dicen que tenían cosas guardadas de la época de los españoles, todavía, que pasaban de generación en generación. Y mi abuelo, bueno, a mi abuelo, hay un lingüista que él — Luis Tovar, se llama el tipo_-, ${ }^{24}$ se llamaba... Eh, él grabó a mi abuelo la forma de hablar, y él hizo, fue el primero que hizo una fonética del idioma. Así que él tiene las... todas las historias que mi abuelo conocía de la época antigua. Y creo que es uno de los pocos libros en que... donde recopila, así, historias ancestrales de los wichí. Hay muchas historias ahí. Mi abuelo Santos, Santos Aparicio. Hay historias, varias historias acá de los wichí. Yo estoy buscando contacto con ese Tovar y encontré por Facebook la familia de ellos y no me contestaron todavía. Voy a insistirles de nuevo, a ver si puedo conseguir la grabación. Mi familia me cuenta que el hombre este andaba con unos discos, así, doble, ¿no?, las cintas. Lo grabó en wichí. Y él le dio la forma escrita. Mi abuelo hablaba en wichí y ahí nomás lo traducía literal, palabra por palabra. En el libro está eso. Ahora, lo lindo es que está del modo... para mí lo más importante es tener algo del abuelo. En una de esas hay más cosas que las que están en el libro. ${ }^{25}$

$* * *$

[E. F.:] Eisejuaz es como un punto de partida, pero está también todo lo que has contado, de la misión, de la historia, del lugar y de tu familia. Ya ves que apareció Santos...

\footnotetext{
${ }^{23}$ Yica es una voz quechua que significa 'morral', y es un bolso cuadrangular tejido en tela de cháguar.

${ }^{24}$ Santos Aparicio fue el principal «informante» de los Relatos y diálogos de lo matacos, de Antonio Tovar.

${ }^{25}$ En efecto, la dedicatoria del libro de Tovar reza así: «A SANTOS APARICIO Y A MIS OTROS INFORMANTES / QUE CON TANTA PACIENCIA FUERON MIS COLABORADORES EN 1958-60 y EN 1970». Y uno de los apartados de la introducción — «Mis informantes»—-dedica un par de páginas a Santos Aparicio (cf. Apéndice 2).
} 
[MARcos:] Incluso mi abuelo Aparicio, como él renunció al espíritu de brujería por tomar este camino, el Evangelio, mis tíos se fueron a buscarlo al monte de nuevo, a hacer invocaciones ancestrales para recuperar el espíritu en la familia. ¿Viste Cleto Flores? Lo conoces, ¿no? Él era también pariente mío. Él era un líder indígena. Fue con mi tío, el hijo mayor de Santos Aparicio, que vive todavía en Buenos Aires. Se fue con él al monte a... El abuelo Santos él dejó... renunció al espíritu, a los espíritus de curandero para... porque adoptó el cristianismo. Incluso en ese tiempo, se cuenta... eso me contó mi abuela, antes de morir, la esposa de él. Que mi abuelo cae enfermo, en eso, cuando era joven todavía, cayó enfermo y no había solución para él, y... orando y... nada. Fue a buscarlo al curandero, a su tío, para que le cure. Y el tío, a la noche anterior que venga el abuelo a su choza, le dijo... le apareció un ángel, no muy grande, y le dijo: «Mañana te va a venir a ver tu sobrino, y si vos le llegás a hacer algo a él, eh, vos vas a morir», le dijo así el ángel. Entonces, al día siguiente, cuando va el abuelo a visitarlo a él, que le cure, el tío le dice: «Vos no podés... yo no te puedo hacer nada a vos, porque ahora ya sos de otro espíritu. Vos ya estás en ese camino y tenés que seguir la enseñanza del gringo», le dice. Y dice que, cuando él hablaba, estaba mi abuelo en la choza y detrás del abuelo estaba el ángel, que solamente el tío lo vio, lo veía. Después, con el tiempo le contó esa historia. Y bueno, ahí, ahí mi abuelo hace renunciamiento a los espíritus familiares. Con el tiempo, ahora, cuando mi abuelo murió, ese espíritu dice que lo... salió de la familia y queda en el aire... Entonces, un tío se ha puesto a hacer un... a hacer un pacto, un rito en el monte, acá, en el río para arriba, en el cerro ahí, con otro pariente de él, que se llamaba Cleto - ya ha muerto también-. Y se han puesto a orarles a los espíritus, pidiéndoles que vuelvan a ellos, que ellos querían seguir. Y decían: «La tontera que ha hecho mi abuelo era renunciar a ese espíritu. Si no lo quería, que lo pase a otro pariente», decían. Pero es, es muy común eso... Bueno, la hija de ese tío, de ese... el hijo mayor de Aparicio, es una curandera allá en la zona de Jujuy. Mucha gente la van a buscar. Así que esa es parte de la leyenda... Y ahora mi tío se hizo cristiano. Él mucho tiempo renegaba del cristianismo de mi abuelo y él, ahora ya de viejo, aceptó el cristianismo. Vive en Buenos Aires, con una hija que, que... No es antropóloga... Arqueóloga, creo que trabaja... Como arqueóloga, creo que... O etnóloga, algo así, una hija de él.

Apéndice 1 [Vicente Aparicio, Tigre y chamán: la Ceremonia del Cebil] $]^{26}$

Yo caminé hasta la casa de Aparicio.

Nada dijo de mi bastón ni de mi aspecto ni de mi desnudez. Me vio parado en la calle, habló a su mujer, y salió a la calle. Y caminamos en la bruta calor.

Ayó, Tigre, Vicente Aparicio, el hombre anciano. Y yo, Eisejuaz, Éste También, el comprado por el Señor.

— ¿A dónde se han ido todos esos que recibiste?

— ¿A dónde? No sé.

- Los mensajeros de la sangre caliente y de la sangre fría. ¿A dónde?

-No sé.

${ }^{26}$ Cf. «La peregrinación» (Gallardo, 2013: 63-65). 
En la bruta calor, llegamos a un lugar donde hay algunos árboles, y nos sentamos para esperar la noche. Cuando vino la noche busqué en mi pantalón unas semillas de de cebil y se las di. Él se quitó un zapato y las puso adentro. Buscamos una piedra, un fierro, y encontramos un pedazo de la calle rota, un cacho de piedra. Y molió las semillas de cebil. Mezcló ese polvo con el tabaco. Y armó un cigarrillo. Y me miró, pero yo ya no tenía mi yesquero. Entonces encendió el cigarrillo. Su alma salió de recorrida. Cantó:

«¿De qué vale la baya, la algarroba del mes de abril? Ya perdió el gusto, ya perdió suavidad, pero ella no eligió la hora de su vida. Debe cumplir. Debe ser molida, alimentar al hombre. Debe caer y sembrarse. Debe cumplir.

"¿De qué vale el hormiguero que quedó en el desmonte, donde la tierra es negra, donde pondrán la caña? ¿De qué vale? La hormiga mira lejos y ve negro. Mira cerca y ve negro. No hay hojas, no hay pastos. Debe cumplir. No eligió la hora de su vida. No eligió su lugar.

»No eligió. No eligió. Debe cumplir. Oh, no eligió. Debe cumplir.

»Se ha dicho: esos chiriguanos ofrecieron mistol, algarroba. Devolvieron favores. Esos matacos dejados, torpes, brutos, pidieron vino, pidieron alcohol, sólo saben pedir.

»No eligió. No eligió. Debe cumplir. No eligió».

He fumado con él, mi alma salió de recorrida, cantó:

«En el centro de la tierra está el viborón. Enrosca las raíces del monte. Duerme con ellas. Nadie eligió, oh no, nadie eligió. Ha caído el monte han muerto los palos, nadie eligió, oh no, nadie eligió, nadie eligió. Sólo ya los palos cantan para Eisejuaz, sólo el aire. Hay que cumplir».

Ha cantado Ayó, su alma que fue de recorrida:

«He visto las últimas mujeres que baten el barro, y amasan, vuelven a amasar y forman el botijo, ese que suena como la campana del gringo, ese redondo como la mujer y el hijo. Y ese alto con tres panzas. Y ese chiquito que lleva el agua al monte. Forman el botijo, y tantos hombres van y compran tarros, van y buscan latas. Pero ellas tienen que amasar, tienen que hacer el botijo hermoso, que suene como la campana del gringo. No eligió la hora de su vida, no eligió, oh no eligió; debe cumplir.

»No lloremos si nuestro tiempo terminó.

»No lloremos, ¿y para qué llorar?

»Morimos juntos: el tigre, el monte, los ríos sueltos como pelos del Señor, y nosotros».

Paró un auto y han gritado:

— ¡Flor de borrachera! ¡Dejen dormir!

Entonces quedamos callados. Ayó me agarró la mano. Sopló adentró de mi boca. Puso de su saliva sobre mi lengua. Caminamos después volviendo para su casa, y pasamos por las calles abiertas de esa ciudad, sin obreros porque era de noche.

Estaba mareado todavía ese hombre anciano, y nos sentamos en la calle.

$[\ldots]$

Cuando los mensajeros de los bichos volvieron a mi corazón me volvió también la fuerza. Caminé rápido, sin el bastón. Fue cuando salió el sol. Salió el sol y me tocó de lejos. Entonces llegaron todos los mensajeros sin faltar uno, sin faltar los bichos de la noche, enemigos del sol. Todos entraron de nuevo en mi corazón, entraron por mi boca, y otros entraron por mi pecho. El Señor me los mandó de vuelta. Yo levanté los brazos, les 
dije: «¿Trajeron sus hamacas, sus fuegos? ¿Están aquí otra vez?». Y agradecí al Señor que me los había mandado de vuelta. ${ }^{27}$

ApÉndice 2 [SAntos Aparicio, Informante e intérprete: la herencia del Tigre] ${ }^{28}$

Santos Aparicio, nacido hacia 1905 en Embarcación, reúne cualidades excelentes como informante. Ya el profesor Palavecino se benefició de sus conocimientos. ${ }^{29}$ Aparicio, inteligente y culto, que ha sido muchos años jardinero de Yacimientos Petrolíferos Fiscales en el Campamento de Vespucio, pocos kilómetros al sur de Tartagal, fue educado por misioneros pentecostales escandinavos. En 1970, vivía jubilado en Tartagal.

Su abuelo fue mago y médico, y la infancia de Aparicio transcurrió en un ambiente en que la convivencia con los colonizadores de la región permitía a los indígenas continuar con su modo de vida y una relativa conservación de su cultura. De su infancia conserva Aparicio la creencia en ciertas supersticiones: asegura haber visto ratones que se convirtieron en murciélagos, y está convencido de que un brujo después de muerto puede convertirse en yacaré o tigre; sabe también de un viejo a las orillas del Bermejo que se hizo enterrar sentado para evitar reaparecer como tigre; ${ }^{30}$ también está convencido de haber visto en el suelo pisadas de duendes.

Pero estos restos aislados de las creencias de su infancia están completamente sumergidos por su adhesión sincera a una secta cristiana. A ella se ha entregado con la profunda religiosidad que parece caracterizar a su pueblo. Aparicio, como en general todos los indígenas protestantes de la región, no sólo pentecostales, sino anglicanos, se abstiene de alcohol y tabaco y coca, y tiene un sentido moral escrupuloso. Fue en su juventud evangelista, es decir, ayudante del misionero sueco Don Jonsson, que dejó en largos años de labor catequética profunda huella en el país. Con él recorrió el Chaco occidental y por él fue educado.

Aparicio lee y escribe bien en español, se interesa en la política y tiene gran disposición para la mecánica. Le atrae la historia y se da cuenta de lo grave que es la desaparición que amenaza a su pueblo y a su lengua. Trabajó conmigo largas horas, estimulado principalmente por la conciencia de que salvaba algo de esa tradición [...].

Recuerdo mis visitas a la casa de la familia en Vespucio, en los veraniegos meses de 1960, aún habitada por varios de sus hijos, donde grabábamos nuestras cintas y se registraban las risas de las niñas más pequeñas, el cacarear de las gallinas, o los golpes de la azuela y el martillo con que su hijo terminaba la barca que el domingo iban a botar en familiar excursión al Bermejo.

Aparicio conservaba en su excelente memoria relatos tradicionales de su gente, y gracias q ello he podido recoger la mayor y mejor parte de mis textos [...]. Con Aparicio trabajé en 1958, y fue mi principal colaborador en mi viaje de julio a septiembre de $1970^{31}$.

\footnotetext{
${ }^{27}$ Reservo para un análisis detenido, el comentario de esta escena chamánica, de canto y ritual — sin olvidar la «información» transmitida por el intérprete-chamán en Relatos y diálogos de los matacos.

${ }^{28} \mathrm{Cf}$. «Mis informantes» (Tovar, 1981: 31-32).

${ }^{29} \mathrm{Cf}$., por ejemplo, Palavecino (1940).

30 «Sin duda se trata de una concepción muy extendida entre las culturas indígenas. Los tobas cuentan de un Kioyí, que vivió en el siglo pasado, que fue sepultado en un pozo, según la usanza, pero en la misma noche del entierro se oyó un bramido de tigre y hallaron al otro día que el sepulcro estaba abierto. Este hombre se había ido a vivir solo al monte y había entablado amistad con los tigres, que le habían concedido grandes poderes» (Tovar, 1981: 31).

${ }^{31}$ En nota a la página de la sección «TEXTOS» del libro, Tovar apunta: «Conservo las cintas magnetofónicas de todos estos textos. Los transcribí y traduje con la ayuda indispensable de los informantes» (Tovar, 1981: 37).
} 


\section{BIBLIOGRAFÍA}

Califano, Mario y Dasso, María Cristina (1999): El chamán wichí, Buenos Aires, Ciudad Argentina.

Califano, Mario y Dasso, María Cristina (1990): «El estado de ensoñación o tohuislek de los matako-maka del Chaco Central (Argentina)», en Antropología y experiencias del sueño, Michel Perrin (coord.), Quito, Abya Yala, pp. 239-261.

Ceriani, César: «Encuentro con Eisejuaz, el soñador soñado», en Boca de Sapo. Arte, Literatura y Pensamiento, 15 abril de 2014.

Ceriani, César y Lavazza, Víctor Hugo (2017): «Por la salvación de los indios: una travesía visual por la misión evangélica de Embarcación, Salta (1925-1975)», en Corpus. Archivos Virtuales de la Alteridad Americana, VII-2, pp. 1-33.

Gallardo, Sara (2013): Eisejuaz, Martín Kohan (pról.), Buenos Aires, El Cuenco de Plata.

Gallardo, Sara (2016): «La historia de Lisandro Vega», en Macaneos. Las columnas de «Confirmado» (1967-1972), Lucía de Leone (ed.), Buenos Aires, Winograd, pp. 275-277.

Montani, Rodrigo (2017): El mundo de las cosas entre los wichís del Gran Chaco. Un estudio etnolingüístico, Cochabamba, Itinerarios.

PAgÉs LARRAYA, Fernando (1959): «La cultura del paricá», en Acta Neuropsiquiátrica Argentina 5, pp. 375-383.

Pagés Larraya, Fernando (1982): Lo irracional en la cultura, 4 volúmenes, Buenos Aires, FECC.

Palavecino, Enrique (1940): «Takjuaj, un personaje mitológico de los matacos», en Revista del Museo de La Plata, nums. 1-7, pp. 245-270.

Palmer, John H (2012): La buena voluntad wichí: una espiritualidad indigena, Rosa María Torlaschi (trad.), Buenos Aires, Asociación para la Promoción de la Cultura y el Desarrollo.

Rosell, Ulises (2012): El etnógrafo [documental], Argentina, Fortunato Films, 86 mins.

Tovar, Antonio (1981): Relatos y diálogos de los matacos, Madrid, Instituto de Cooperación Iberoamericana.

Wright, Pablo (2015): «Sueño, shamanismo y Evangelio en los qom (tobas) del Chaco argentino», en Sociedad y Religión, XXV-44, pp. 30-61.

Wright, Pablo (2008): Ser-en-el-sueño. Crónicas de historia y vida toba, Buenos Aires, Biblos.

Fecha de recepción: 9 de septiembre de 2019

Fecha de aceptación: 3 de diciembre de 2019

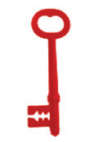

